\title{
Chemotherapy-related complications in the kidneys and collecting system: an imaging perspective
}

\author{
Jemianne Bautista $\mathrm{Jia}^{1}$ (1) Chandana Lall $^{1} \cdot$ Temel Tirkes $^{2} \cdot$ Rajesh Gulati $^{3}$. \\ Ramit Lamba $^{4} \cdot$ Scott C. Goodwin ${ }^{1}$
}

Received: 19 January 2015 /Revised: 3 June 2015 / Accepted: 16 June 2015 / Published online: 11 July 2015

(C) The Author(s) 2015. This article is published with open access at Springerlink.com

\begin{abstract}
Nephrotoxicity is a common adverse effect of many chemotherapeutic agents. The agents most commonly associated with chemotherapy-associated nephrotoxicity are methotrexate, semustine, streptozocin, mithramycin, and cisplatin. Certain chemotherapeutic agents have adverse effects on the kidneys and urothelium that can be visualized radiographically, including cystic change, interstitial nephritis, papillary necrosis, urothelial changes, haemorrhagic cystitis, acute tubular necrosis, and infarction. This review focuses on imaging features identifying complications of chemotherapy in the kidneys and collecting system and provides didactic cases to alert referring clinicians.
\end{abstract}

Jemianne Bautista Jia

jemtbautista@gmail.com

1 Department of Radiology, University of California, Irvine School of Medicine, 101 The City Drive South, Mail Code: 5005, Orange, CA 92868, USA

2 Department of Radiology, Indiana University School of Medicine, 714 N. Senate Avenue, Suite 100, Indianapolis, IN 46202, USA

3 Department of Internal Medicine, University of California, Irvine School of Medicine, 101 The City Drive, Mail Code: 4076, Orange, CA 92868, USA

4 Department of Radiology, University of California, Davis School of Medicine, 2315 Stockton Blvd., Sacramento, CA 95817, USA
Teaching Points

- Nephrotoxicity is a common adverse effect of many chemotherapeutic agents.

- Chemotherapies have adverse renal and urothelial effects that can be visualized radiographically.

- Crizotinib use can result in the development of complex renal cysts.

Keywords Chemotherapy · Biologic agents ·

Nephrotoxicity $\cdot$ Renal cysts $\cdot$ Drug-associated adverse effects

\section{Introduction}

Nephrotoxicity is a common adverse effect of many chemotherapeutic agents. A major contributing factor is the renal excretion of the majority of these agents. Damage is often identifiable clinically by changes in glomerular filtration rate, creatinine clearance, blood urea nitrogen, urine protein, and urine output. The most common agents causing chemotherapy-associated nephrotoxicity include cisplatin, methotrexate, mithramycin semustine, and streptozocin. Certain chemotherapeutic agents have adverse renal and urothelial effects that can be visualized radiographically including cystic change, interstitial nephritis, papillary necrosis, urothelial changes, haemorrhagic cystitis, acute tubular necrosis (ATN), and infarction. This review focuses on imaging features identifying complications of chemotherapy in the kidneys and collecting system and provides didactic cases to alert referring clinicians (Table 1). 
Table 1 Table summarizing adverse effects in the kidneys and collecting system visible on imaging and associated cancer therapies

\begin{tabular}{|c|c|c|c|}
\hline Adverse effect & Associated agents & Laboratory findings & Radiologic findings \\
\hline Complex renal cysts & Crizotinib & None & $\begin{array}{l}\text { US- Ovoid, anechoic cysts with clearly } \\
\text { demarcated walls, no septa or calcifications, } \\
\text { near water density } \\
\text { CT- Bosniak III-IV complex cysts }\end{array}$ \\
\hline \multirow[t]{3}{*}{ Interstitial nephritis } & \multirow[t]{3}{*}{$\begin{array}{l}\text { Ipilimumab } \\
\text { Sorafenib }\end{array}$} & $\begin{array}{l}\uparrow \text { Plasma creatinine } \\
\text { Azotemia }\end{array}$ & $\begin{array}{l}\text { Urography- Enlarged kidneys, dense persistent } \\
\text { nephrogram }\end{array}$ \\
\hline & & $\begin{array}{l}\mathrm{FENa}>1 \% \\
\text { Eosinophiluria }\end{array}$ & $U S$ - Enlarged kidneys \\
\hline & & $\begin{array}{l}\text { Proteinuria } \\
\text { Pyuria }\end{array}$ & $\begin{array}{l}\text { CT- Renal edema and enlargement, streaky } \\
\text { parenchymal low-attenuation areas }\end{array}$ \\
\hline \multirow[t]{3}{*}{ Renal papillary necrosis } & \multirow[t]{3}{*}{ Nedaplatin } & $\begin{array}{l}\uparrow \text { Plasma creatinine } \\
\text { Azotemia } \\
\text { Leukocytosis } \\
\text { Hematuria }\end{array}$ & $\begin{array}{l}\text { Urography- Irregular contour of the renal papillae } \\
\text { and widening of the fornixes, "ball on a tee sign" }\end{array}$ \\
\hline & & \multirow[t]{2}{*}{ Pyuria } & $\begin{array}{l}\text { US- Multiple cystic spaces in the medullary region } \\
\text { arranged around the renal sinus, non-shadowing } \\
\text { soft tissue masses within the ureter }\end{array}$ \\
\hline & & & $\begin{array}{l}C T \text { - Excavation of the calyces, regression of the papillae, } \\
\text { blunting of the calyces, detached papillae in the ureter }\end{array}$ \\
\hline \multirow[t]{3}{*}{ Renal infarction } & \multirow{3}{*}{$\begin{array}{l}\text { Methotrexate } \\
\text { Combination Cisplatin } \\
\text { and Gemcitabine Regimens }\end{array}$} & \multirow{3}{*}{$\begin{array}{l}\uparrow \text { Lactate dehydrogenase } \\
\text { Hematuria } \\
\text { Proteinuria }\end{array}$} & \multirow{3}{*}{$\begin{array}{l}\text { Urography- Absence of contrast material in infarcted } \\
\text { parenchyma } \\
\text { US- Heterogeneity of parenchyma } \\
\text { CT- Low attenuation, wedge shaped areas in the cortex, } \\
\text { "rim sign" }\end{array}$} \\
\hline & & & \\
\hline & & & \\
\hline \multirow[t]{5}{*}{ Acute tubular necrosis } & \multirow[t]{5}{*}{$\begin{array}{l}\text { Cisplatin } \\
\text { Ifosfamide } \\
\text { Imatinib }\end{array}$} & $\downarrow$ GFR & \multirow{2}{*}{$\begin{array}{l}\text { Urography- Renal enlargement with prolonged } \\
\text { opacification of the renal parenchyma, increase } \\
\text { in density of the pyramids } \\
\text { US- Cortical echogenicity }\end{array}$} \\
\hline & & & \\
\hline & & $\downarrow$ Urine osmolality & \multirow[t]{3}{*}{ CT- Contrast retention in the parenchyma, "rim sign" } \\
\hline & & $\downarrow$ Urine/plasma creatinine ratio & \\
\hline & & $\begin{array}{l}\text { Urine sediment: renal tubular epithelial } \\
\text { cells, epithelial cell casts, and muddy } \\
\text { brown granular casts }\end{array}$ & \\
\hline \multirow[t]{3}{*}{ Chemotherapy cystitis } & \multirow[t]{3}{*}{ Intravesical Mitomycin C } & \multirow[t]{3}{*}{ Hematuria } & $\begin{array}{l}\text { Urography-Small bladder with thickened walls, } \\
\text { calcifications within the walls may be present }\end{array}$ \\
\hline & & & $\begin{array}{l}\text { CT- Diffuse or focal irregular bladder wall thickening, } \\
\text { decreased bladder volume and perivesical fat, edema }\end{array}$ \\
\hline & & & MRI- High T2 signal within the bladder wall \\
\hline \multirow[t]{3}{*}{ Hemorrhagic cystitis } & $\begin{array}{l}\text { Cyclophosphamide } \\
\text { Ifosphamide }\end{array}$ & \multirow[t]{3}{*}{ Hematuria } & \multirow[t]{3}{*}{ CT- Bladder wall thickening } \\
\hline & Busulfan & & \\
\hline & Cabazitaxel & & \\
\hline
\end{tabular}

\section{Effects of chemotherapeutic agents on cross-sectional imaging of the kidney}

\section{Complex renal cysts}

The development of complex renal cysts associated with crizotinib treatment is well documented in the literature. Crizotinib is an anaplastic lymphoma kinase (ALK) inhibitor used in the treatment of ALK positive metastatic non-small cell lung cancer (NSCLC). Lin et al. explored the presence of complex renal cysts in patients enrolled in prospective clinical trials for crizotinib treatment. In the 32 patients included in the study, $13 \%$ developed new complex renal cysts and $22 \%$ had significant renal cyst change following initiation of crizotinib treatment. After cessation of crizotinib treatment, the cysts were found to regress significantly [1]. In a similar retrospective study, Schnell et al. reported that of 17 patients found with complex renal cysts associated with crizotinib use, 11 required hospitalization due to the cysts, with seven having cystic invasion into adjacent structures in the form of inflammatory 
cystic masses. The majority of patients were asymptomatic, but a small number presented with flank pain or fevers [2].

\section{Imaging findings}

Urography cannot be used to definitively diagnose complex cysts as they present as indiscernible masses when this technique is used [3]. Sonographically, cysts associated with crizotinib have been described as ovoid, anechoic with internal echoes, near-water density, with smooth clearly demarcated walls and acoustic enhancement behind the cysts, and without septa or calcifications [4]. On ultrasound (US), diagnosis of cysts may be complicated by a number of factors. Vascular malformations or aneurysms could be mistaken for cystic disease if real-time studies do not demonstrate pulsations or large feeding vessels are not delineated. In addition, peripelvic cysts often contain artificially created echoes due to their proximity to structures of the collecting system and need to be confirmed on computed tomography (CT) [3].

On CT, complex renal cysts can be distinguished from benign cysts using criterion laid out by Bosniak. The presence of extensive calcification, septa with irregular walls thicker than $1 \mathrm{~mm}$ or associated with solid elements at their attachments, hyperdense fluid with irregularity of contour or hazy margination, internal haemorrhage or debris, and thickening or irregularity of the wall or any evidence of solid tissue within the wall distinguish complex from benign cysts (Fig. 1a-c) [3]. Cysts associated with crizotinib use have been reported as Bosniak classification types II-IV [1, 4]. Bosniak II cysts are well marginated and characterized by a few thin septa less than $1 \mathrm{~mm}$ and thin calcifications. Bosniak III cysts are characterized by thick or multiple septations, mural nodule, and are hyperdense on CT. Bosniak IV cysts are characterized as solid masses with large cystic or necrotic components, irregular margins, and solid vascular elements [2]. Complex cysts may mimic metastatic disease and it is thus important to have knowledge of this entity (Fig. 1d-e). On examination of cysts with $\mathrm{CT}$, it is important to obtain pre- and postcontrast imaging so that calcifications and recent haemorrhage can be identified and so high-density non-enhancing renal cysts are not mistaken for solid metastatic lesions. If enhancement is present, renal abscesses and metastases are included in the differential. It is imperative for diagnosis on CT that the fluid in the cyst is near water density with a suggested upper threshold of $20 \mathrm{HU}$. If the density exceeds $20 \mathrm{HU}$, other pathologies such as tumours need to be considered [3]. CT and magnetic resonance imaging (MRI) findings of complex renal cysts are equivalent with the two techniques resulting in similar ratings based on the Bosniak system [5].

\section{Interstitial nephritis}

Interstitial nephritis refers to inflammation of the renal interstitium. Histologically, this is characterized by interstitial infiltration by lymphocytes, monocytes, and granulomas. Symptoms may include oliguria and less commonly, hematuria. Patients may also have nonspecific symptoms of fever, rash, and loin pain, but in many cases patients are asymptomatic [6]. Interstitial nephritis can be associated with a decline in creatinine clearance, eosinophilia, eosinophiluria, and proteinuria. Multiple chemotherapy regimens have been associated with interstitial nephritis, most notably ipilimumab. In ipilimumab-induced interstitial nephritis, patients are treated with prednisone and quickly return to their baseline kidney function [7].

\section{Imaging findings}

On urography, acute interstitial nephritis often reveals enlarged kidneys as well as an early, dense, persistent nephrogram, which is similar to the findings of ATN. An important distinguishing characteristic is that ATN results in normal sized or only slightly enlarged kidneys [8]. On US imaging, acute interstitial nephritis may not be apparent or may present with enlargement of the kidneys as well [9]. CT findings include renal oedema and enlargement. The presence of streaky parenchymal low-attenuation areas, which may mimic more common entities like pyelonephritis and multifocal infarcts among others, may also be seen (Figs. 2a, b, and 3) [10]. Radiographic findings are not diagnostic of interstitial nephritis and findings need to be confirmed with biopsy. However, imaging is useful in excluding obstruction that would require decompression.

\section{Renal papillary necrosis}

Renal papillae are present at the apex of the renal pyramid at the site where urine is discharged from the renal tubules. Papillary necrosis occurs secondary to ischemia and can be triggered by a number of factors, the most common ones being analgesic nephropathy, diabetes, sickle cell disease, and infection. Histologically, renal papillary necrosis (RPN) appears as coagulative necrosis, characterized by a pale centre with surrounding inflammatory cells [11]. Symptoms of RPN most commonly include fevers, chills, flank pain, and hematuria. Sloughed papillae can cause ureteral obstruction and hydronephrosis, further worsening renal function. The platinum based agents, cisplatin and nedaplatin, are associated with RPN [12]. Care needs to be taken in interpretation of this pathological outcome as it can be difficult to determine whether the cause is the chemotherapy itself or chronic analgesic use since cancer patients are often on powerful analgesic regimens. 
Fig. 1 Forty-nine-year-old female with NSCLC being treated with long-term crizotinib therapy. (a) Pre-treatment axial CT with normal renal findings. (b, c) Axial and coronal CT images, respectively, performed 3 years following initiation of treatment with crizotinib revealing multiple complex cystic lesions bilaterally (arrows). (d) Axial positron emission tomography (PET)/CT without evidence of abnormal FDG-avid uptake supporting a benign process. (e, f) Axial PET/ $\mathrm{CT}$ of a different patient with abnormal FDG-avid uptake positive for renal neoplasm provided as comparison (arrows)
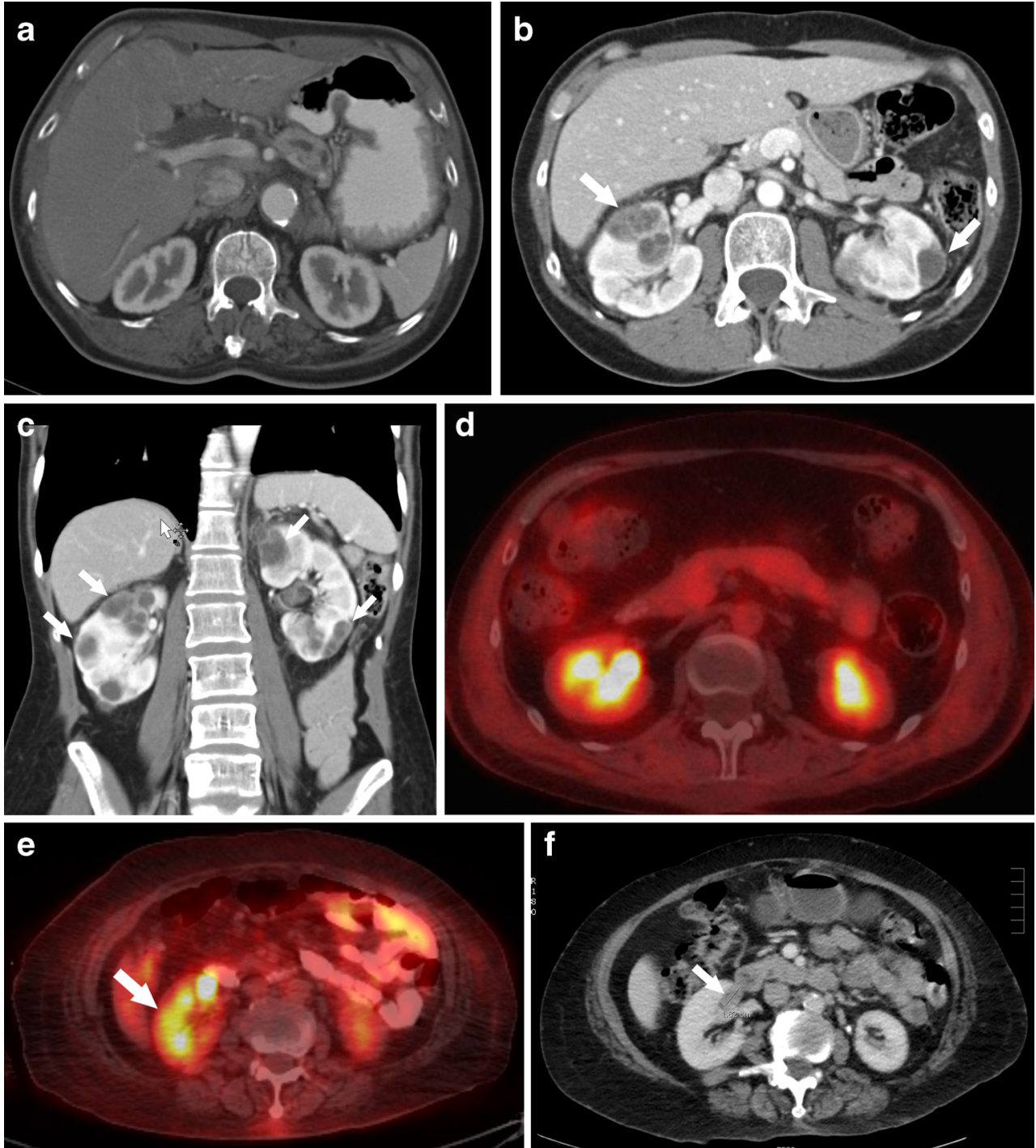

\section{Imaging findings}

Urographic findings are diagnostic with irregular contour of the renal papillae and widening of the fornixes (Fig. 4a). After sloughing of the papilla, contrast penetrates the renal parenchyma and ring shaped shadows appear to demonstrate the detached papilla, the so-called ball on a tee sign [13]. Sonographically, renal papillary necrosis appears as multiple cystic spaces in the medullary region arranged around the renal sinus echoes [14]. Necrosed papilla appear as nonshadowing soft tissue masses within the ureter which cannot be differentiated from other pathologies such as blood clots [14]. Hydronephrosis which has similar findings can be differentiated from renal papillary necrosis by the presence of a central dilation of the pelvis [15]. On CT, renal papillary necrosis is characterized by excavation of the calyces, regression of the papillae, detached papilla in the ureter, and blunting of the calyces (Fig. 4b) [16].

\section{Renal infarction}

Renal infarction presents with persistent pain often resistant to analgesia, nausea and vomiting, proteinuria, hematuria, and elevated lactate dehydrogenase [17]. In the literature, it has been reported with use of methotrexate and combination regimens of cisplatin and gemcitabine $[18,19]$. In a case series with 44 patients with long-term follow-up for renal infarction, $61 \%$ of patients regained normal renal function while the remaining patients alive at follow-up had progressed to irreversible kidney dysfunction [20].

\section{Imaging findings}

Urography findings for renal infarction vary according to the severity. Small infarcts often present with normal urograms. With more severe lesions, there can be an absence of contrast material in the ischemic renal 
Fig. 2 Forty-three-year-old male with soft tissue sarcoma, on a combination high-dose cisplatin chemotherapy regimen. (a) Prechemotherapy coronal CT showing normal renal findings. (b) Post-chemotherapy coronal CT showing an interstitial nephritis pattern with enlargement of the kidneys and multiple hypoattenuating lesions, more prominent in the right kidney (arrow)
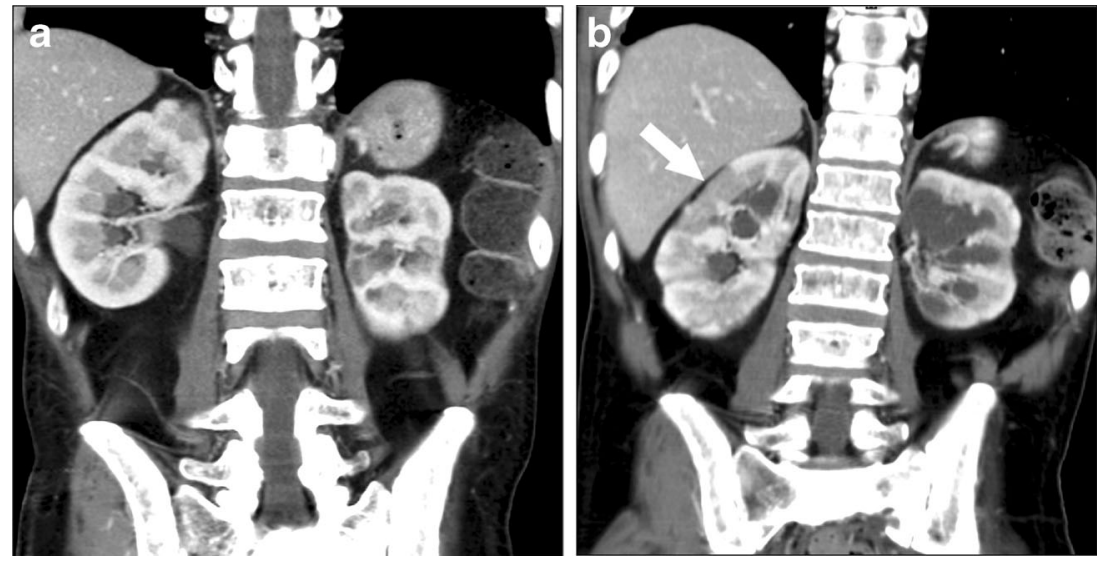

parenchyma with local failure of calyceal filling of the affected tissue during the pyelographic phase. Renal infarction may also result in vasospasm which presents as complete nonvisualization of the kidney [21]. On US, acute renal infarcts may be non-specific in appearance, with heterogeneity of the parenchyma. Chronic infarcts may be wedge shaped and hypoechoic with cortical scarring [22]. On CT, renal infarcts appear as low attenuation, wedge shaped areas in the cortex (Fig. 5a, b). Sometimes the "rim sign" is present, which is a higher-attenuation subcapsular rim surrounding lowerattenuation infarcted renal parenchyma representing subcapsular perfusion through collateral flow [23, 24]. However, as the "rim sign" is a universal and highly specific indicator of renovascular compromise, it can also be present in acute tubular necrosis and renal vein thrombosis. Hydronephrosis similarly is characterized by a "rim sign"; however, this rim sign can be distinguished from that of vascular compromise by its variable thickness, medial concavity, and location surrounding the dilated calices in communication with the central pelvis [25].

\section{Acute tubular necrosis}

ATN refers to acute renal failure caused by an ischemic or toxic insult to the tubular epithelial cells. This results in epithelial cell detachment from the basement membrane causing tubular dysfunction. It presents with a decrease in GFR, urine osmolality, and urine/plasma creatinine ratio. Urine sediment is characterized by renal tubular epithelial cells, epithelial cell casts, and muddy brown granular casts [26]. ATN is associated with cisplatin and ifosfamide treatment $[27,28]$. Patients may return to baseline kidney function following ATN; however, some patients develop an irreversible decline in function. Risk factors for permanent injury include age over 65 years, atheroembolic disease, and preexisting chronic kidney disease. ATN that develops in the hospital setting is associated with a high mortality rate $[29,30]$.

\section{Imaging findings}

On urography, acute tubular necrosis appears as renal enlargement with prolonged opacification of the renal parenchyma and an increase in density of the pyramids [31]. On sonography, ATN presents as increased cortical echogenicity [32]. Inadequacy of perfusion can also be detected as abnormal Doppler velocity waveforms [33]. On CT imaging, ATN presents with contrast retention in the parenchyma (Fig. 6a, b). The "rim sign" can also be used to characterize ATN and is a valuable factor distinguishing infarction from pyelonephritis [25].

\section{Effects of chemotherapeutic agents on cross-sectional imaging of the collecting systems}

\section{Chemotherapy-induced cystitis}

Chemotherapy-induced cystitis is characterized by epithelial proliferation following chemotherapy treatment. A study

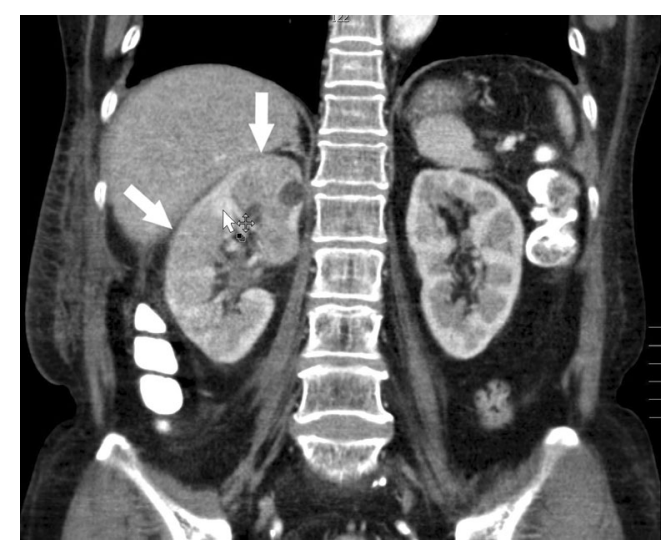

Fig. 3 Sixty-five-year-old female with multiple myeloma being treated with a combination chemotherapy regimen that included carmustine. Post-chemotherapy CT showing bilateral enlarged kidneys and a hypoattenuating lesion in the right kidney (arrows) consistent with interstitial nephritis 
Fig. 4 Sixty-two-year-old woman with node positive ductal carcinoma undergoing treatment with carboplatin and paclitaxel. (a) Coronal maximum intensity projection (MIP) image showing bilateral blunting of the calices consistent with renal papillary necrosis. (b) CT-urographic image demonstrating bilateral irregularly shaped, projections at the apex of the left renal pyramids suggestive of papillary necrosis
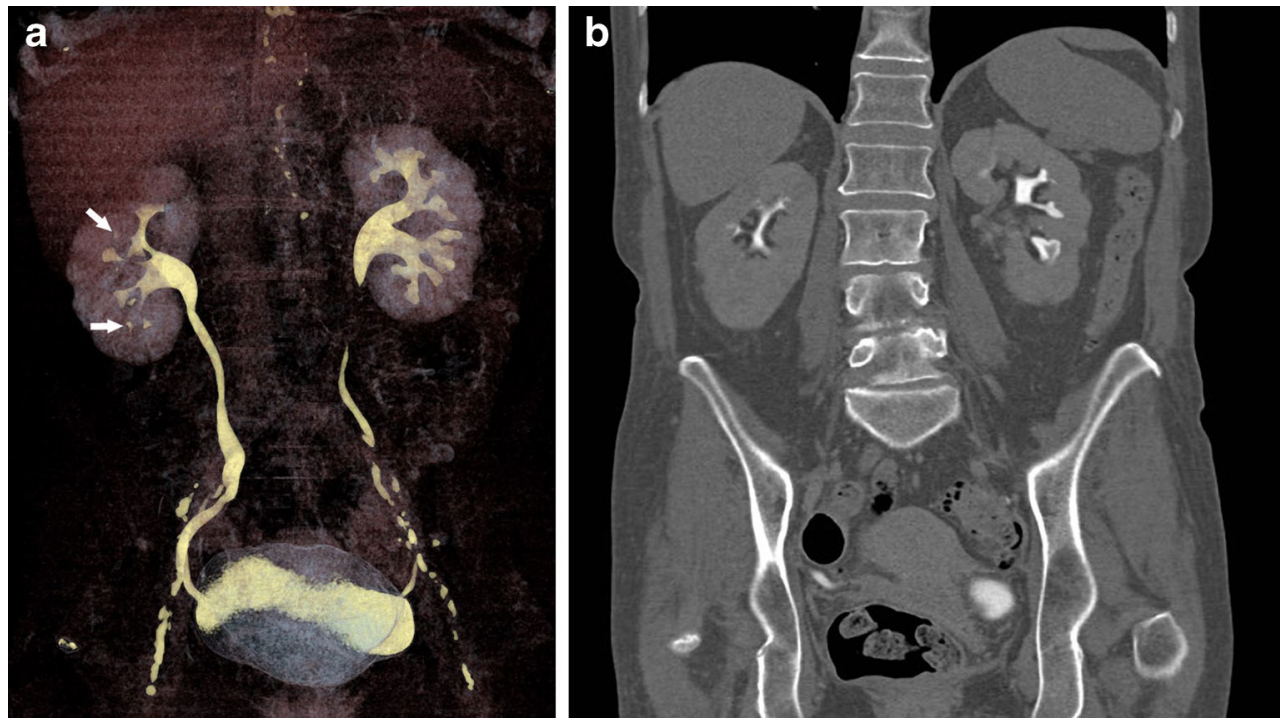

looking at 17 cases of both chemotherapy- and radiationinduced cystitis histologically characterized the cystitis as epithelial proliferation within the lamina propria with mild to moderate nuclear pleomorphism without mitoses. Pseudoinvasive urothelial nests wrapping around vessels, haemorrhage, fibrin, deposition, and acute and chronic inflammation were also present in all cases. All patients presented with hematuria with the presentation of symptoms occurring anywhere from mid-chemotherapy treatment to as far as 60 days following treatment cessation in patients with chemotherapy-induced cystitis. All patients available for follow-up at 9 months had an improvement in their hematuria and $71 \%$ had negative cystoscopies at this time. No patients went on to develop bladder cancer [34]. Chemotherapy cystitis is associated with intravesical use of mitomycin C [35].

\section{Imaging findings}

Radiologic findings of chemotherapy-induced cystitis are nonspecific and cannot be distinguished from other causes of cystitis. On intravenous urography and cystography, the bladder may be small with thickened walls. Rarely, calcifications can be present within the wall [36]. On CT imaging, acute chemotherapy-induced cystitis may present with diffuse or focal irregular bladder wall thickening, decreased bladder volume and perivesical fat, and oedema. Increased contrast enhancement of the bladder wall is not usually present [36]. On MRI, there is high T2 signal intensity within the bladder wall, which is suggestive of inflammation [37]. Increased signal intensity of the mucosa may also be seen on T1-weighted images and is likely attributable to mucosal haemorrhage [36].

\section{Hemorrhagic cystitis}

Hemorrhagic cystitis is inflammation of the bladder that is characterized by mucosal hyperemia, ulcerations, haemorrhage, and necrosis. Symptoms consist of hematuria, frequency, dysuria, burning, urgency, incontinence, and nocturia [38]. Hemorrhagic cystitis is highly associated with oxazaphosphorine compounds, especially cyclophosphamide and ifosphamide [39]. Busulfan [40] and cabazitaxel [41] are also implicated. Mesna and continuous bladder irrigation and
Fig. 5 Fifty-four-year-old male with testicular cancer presenting with evidence of renal infarct following four cycles of bleomycin, etoposide, and cisplatin. (a) Pre-treatment coronal CT showing normal appearance of the kidneys. (b) Post-treatment coronal CT showing developing left renal infarct appearing as an area of hypoattenuation in the inferior aspect (arrow)
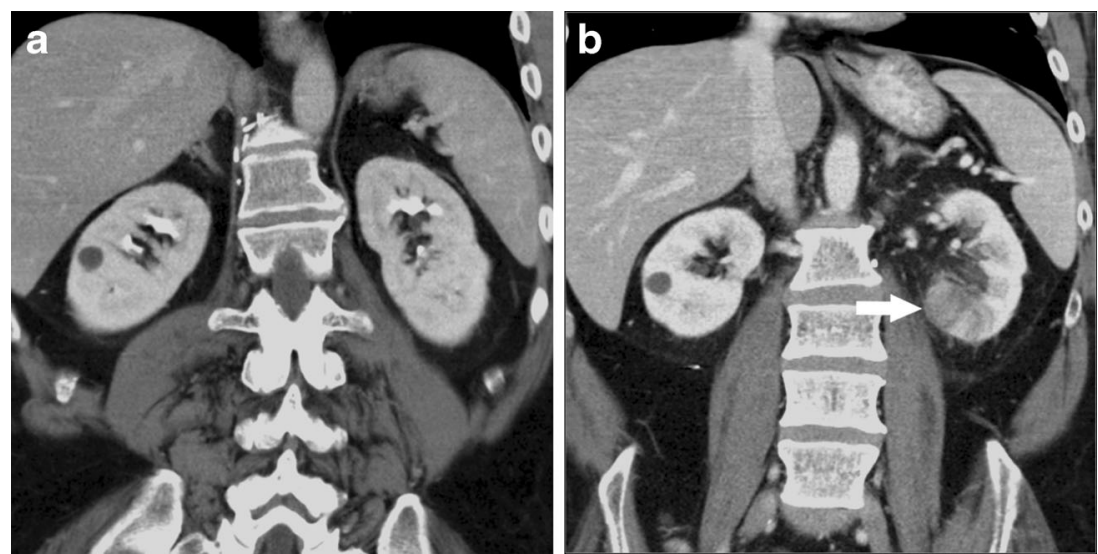
Fig. 6 Eighty-year-old woman with gastric cancer mid-treatment with cisplatin and 5-FU. (a) Pretreatment axial CT demonstrating normal renal characteristics. (b) Noncontrast axial CT demonstrating contrast retention in the right renal parenchyma consistent with ATN (arrow)
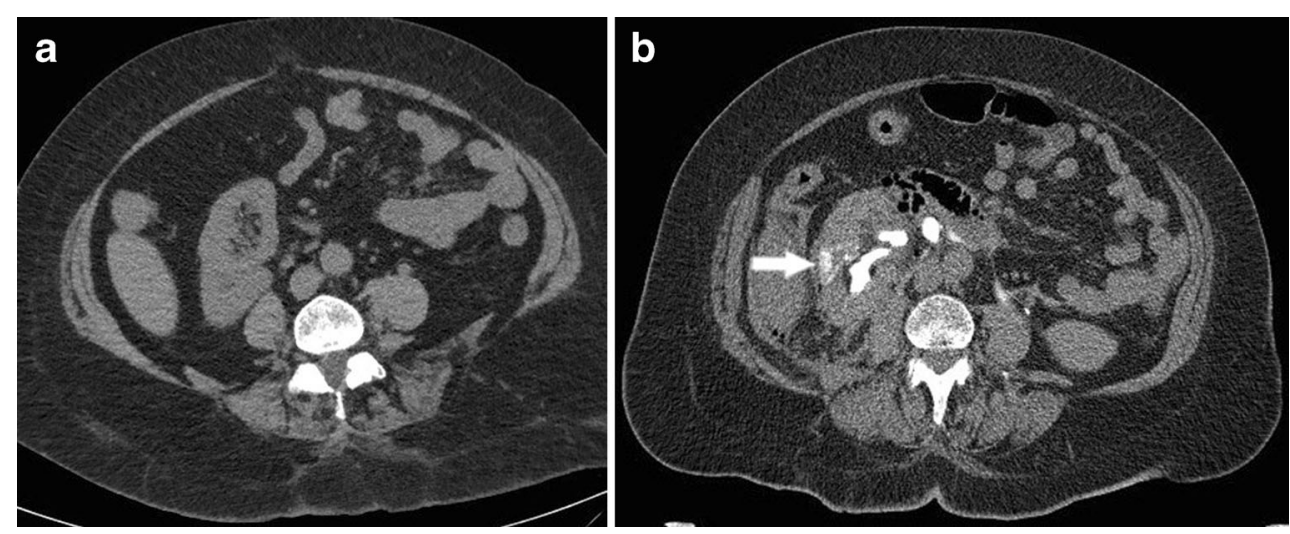

hyperhydration have been shown to be effective in preventing cyclophosphamide-induced hemorrhagic cystitis [42, 43]. Hemorrhagic cystitis caused by chemotherapeutic agents is generally reversible following cessation of the offending agent.

\section{Imaging findings}

Excretory urograms can be normal in hemorrhagic cystitis [38]. US is a useful technique in evaluation of hemorrhagic cystitis as power Doppler allows estimations of the hypervascularity, and thus the severity of the condition [44]. Hemorrhagic cystitis appears as bladder wall thickening on CT (Fig. 7a, b) [45]. However, as the imaging characteristics are not specific, they need to be correlated clinically with hematuria, which is the most common presenting symptom.

\section{Effects of novel targeted agents on the kidney and collecting systems}

Cancer therapy has been moving in the direction of targeted therapies. As evidence surfaces for these novel agents, many are found to have renal toxicities. Antiangiogenic compounds such as bevacimumab, sunitinib, and sorafenib, which inhibit the VEGF pathway, are associated with proteinuria, increased levels of creatinine, and hypertension. MET inhibitors in phase II trials have also been found to be associated with proteinuria and hypertension. The EGFR inhibitors, erlotinib, cituximab, and gefitinib, and the HER2 inhibitors, trastuzumab and lapatinib, have not been associated with any renal toxicities.

Adverse effects associated with newer targeted agents visible radiographically include interstitial nephritis reported with sorafenib treatment and tubular necrosis reported with imatinib treatment [46].

\section{Conclusion}

Chemotherapy is vital in the treatment of cancer. However, its inherent toxicity often has unintended adverse effects. The kidney and collecting system are commonly involved due to their role in filtration and elimination. Chemotherapy can cause various changes including complex renal cysts, interstitial nephritis, urothelial irritation, acute and chronic tubular necrosis, and renal infarction, among others. Aside from complex renal cysts associated with crizotinib use, the pathologies elaborated on in this manuscript are often symptomatic and

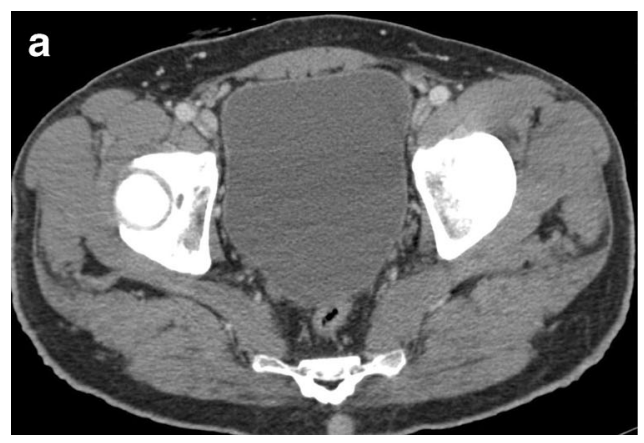

Fig. 7 Forty-four-year-old male with non-Hodgkin's lymphoma status post treatment with cyclophosphamide. (a) Axial CT pre-chemotherapy image showing normal bladder findings. (b) Axial CT image showing

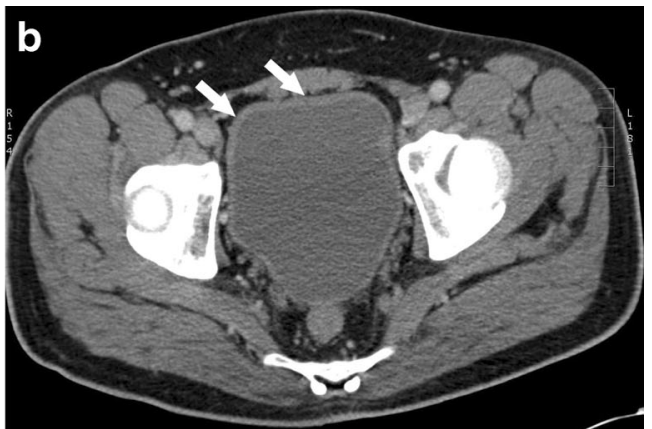

thickened urinary bladder wall consistent with chemotherapy induced hemorrhagic cystitis (arrows) 
can negatively impact renal or collecting system function. Therefore, if imaging suggestive of these pathologies arises, renal function tests need to be performed and regimens adjusted accordingly. With complex cysts secondary to crizotinib use, regression occurs spontaneously following treatment. However, if patients are symptomatic or if invasion into surrounding structures is noted on imaging, then further evaluation and medication adjustments need to be made. Familiarization with imaging features consistent with postchemotherapy changes to the kidneys and urothelium and subsequent recognition and reporting will improve clinical monitoring of patients, early detection of chemotherapyassociated complications, and will ultimately result in improved patient care and outcomes through modification, interruption, or suspension of therapy.

Open Access This article is distributed under the terms of the Creative Commons Attribution 4.0 International License (http:// creativecommons.org/licenses/by/4.0/), which permits unrestricted use, distribution, and reproduction in any medium, provided you give appropriate credit to the original author(s) and the source, provide a link to the Creative Commons license, and indicate if changes were made.

\section{References}

1. Lin YT, Wang YF, Yang JC, Yu CJ, Wu SG, Shih JY et al (2014) Development of renal cysts after crizotinib treatment in advanced ALK-positive non-small-cell lung cancer. J Thorac Oncol: Off Publ Int Assoc Study Lung Cancer 9(11):1720-1725

2. Schnell P, Bartlett CH, Solomon BJ, Tassell V, Shaw AT, de Pas T et al (2015) Complex renal cysts associated with crizotinib treatment. Cancer Med

3. Bosniak MA (1986) The current radiological approach to renal cysts. Radiology 158(1):1-10

4. Souteyrand P, Burtey S, Barlesi F (2014) Multicystic kidney disease: a complication of crizotinib. Diagn Interv Imaging

5. Israel GM, Hindman N, Bosniak MA (2004) Evaluation of cystic renal masses: comparison of $\mathrm{CT}$ and MR imaging by using the Bosniak classification system. Radiology 231(2):365-371

6. Clarkson MR, Giblin L, O'Connell FP, O'Kelly P, Walshe JJ, Conlon P et al (2004) Acute interstitial nephritis: clinical features and response to corticosteroid therapy. Nephrol Dial Transplant: Off Publ Eur Dial Transplant Assoc - Eur Renal Assoc 19(11): 2778-2783

7. Izzedine H, Gueutin V, Gharbi C, Mateus C, Robert C, Routier E et al (2014) Kidney injuries related to ipilimumab. Investig New Drugs 32(4):769-773

8. Pusey CD, Saltissi D, Bloodworth L, Rainford DJ, Christie JL (1983) Drug associated acute interstitial nephritis: clinical and pathological features and the response to high dose steroid therapy. Q J Med 52(206):194-211

9. Hoppes T, Prikis M, Segal A (2007) Four cases of nafcillinassociated acute interstitial nephritis in one institution. Nat Clin Pract Nephrol 3(8):456-461

10. Raissian Y, Nasr SH, Larsen CP, Colvin RB, Smyrk TC, Takahashi $\mathrm{N}$ et al (2011) Diagnosis of IgG4-related tubulointerstitial nephritis. J Am Soc Nephrol: JASN 22(7):1343-1352
11. Lager DJ, Abrahams NA (2013) Practical renal pathology: a diagnostic approach. Elsevier/Saunders, Philadelphia, p 368

12. Uehara T, Yamate J, Torii M, Maruyama T (2011) Comparative nephrotoxicity of cisplatin and nedaplatin: mechanisms and histopathological characteristics. J Toxicol Pathol 24(2):87-94

13. Lindvall N (1978) Radiological changes of renal papillary necrosis. Kidney Int 13(1):93-106

14. Vijayaraghavan SB, Kandasamy SV, Mylsamy A, Prabhakar M (2003) Sonographic features of necrosed renal papillae causing hydronephrosis. J Ultrasound Med: Off J Am Inst Ultrasound Med 22(9):951-956, quiz 7-8

15. Hoffman JC, Schnur MJ, Koenigsberg M (1982) Demonstration of renal papillary necrosis by sonography. Radiology 145(3):785-787

16. Jung DC, Kim SH, Jung SI, Hwang SI, Kim SH (2006) Renal papillary necrosis: review and comparison of findings at multidetector row $\mathrm{CT}$ and intravenous urography. Radiographics: Rev Publ Radiol Soc North Am, Inc 26(6):1827-1836

17. Domanovits H, Paulis M, Nikfardjam M, Meron G, Kurkciyan I, Bankier AA et al (1999) Acute renal infarction. Clinical characteristics of 17 patients. Medicine 78(6):386-394

18. Yokoyama M, Okamoto M, Oda T, Ochi K, Takeuchi M (1984) Renal infarction caused by chemotherapy for chorioepithelioma. Urol Int 39(3):187-188

19. Cavdar C, Toprak O, Oztop I, Secil M, Cokmert S, Camsari T (2007) Bilateral renal infarction in a patient with lung carcinoma treated with cisplatin and gemcitabine. Ren Fail 29(7):923-925

20. Hazanov N, Somin M, Attali M, Beilinson N, Thaler M, Mouallem $\mathrm{M}$ et al (2004) Acute renal embolism. Forty-four cases of renal infarction in patients with atrial fibrillation. Medicine 83(5):292299

21. Lisbona R, Derbekyan V, Rosenthall L (1981) Observations on renal scanning and intravenous urography in acute segmental renal infarction. Clin Nucl Med 6(6):253-257

22. Martin KW, McAlister WH, Shackelford GD (1988) Acute renal infarction: diagnosis by Doppler ultrasound. Pediatr Radiol 18(5): 373-376

23. Glazer GM, Francis IR, Brady TM, Teng SS (1983) Computed tomography of renal infarction: clinical and experimental observations. AJR Am J Roentgenol 140(4):721-727

24. Demos TC, Gadwood K, Love L, Engel G (1982) The rim nephrogram in renovascular compromise. Urol Radiol 4(4):227230

25. Saunders HS, Dyer RB, Shifrin RY, Scharling ES, Bechtold RE, Zagoria RJ (1995) The CT nephrogram: implications for evaluation of urinary tract disease. Radiographics: Rev Publ Radiol Soc North Am, Inc 15(5):1069-1085, discussion 86-8

26. Gill N, Nally JV Jr, Fatica RA (2005) Renal failure secondary to acute tubular necrosis: epidemiology, diagnosis, and management. Chest 128(4):2847-2863

27. Goldstein RS, Mayor GH (1983) Minireview. The nephrotoxicity of cisplatin. Life Sci 32(7):685-690

28. de Jonge MJ, Verweij J (2006) Renal toxicities of chemotherapy. Semin Oncol 33(1):68-73

29. Bucaloiu ID, Kirchner HL, Norfolk ER, Hartle JE 2nd, Perkins RM (2012) Increased risk of death and de novo chronic kidney disease following reversible acute kidney injury. Kidney Int 81(5):477-485

30. Schmitt R, Coca S, Kanbay M, Tinetti ME, Cantley LG, Parikh CR (2008) Recovery of kidney function after acute kidney injury in the elderly: a systematic review and meta-analysis. Am J Kidney Dis: Off J Natl Kidney Found 52(2):262-271

31. Chrispin AR, Hull D, Lillie JG, Ridson RA (1970) Renal tubular necrosis and papillary necrosis after gastroenteritis in infants. $\mathrm{Br}$ Med J 1(5693):410-412

32. Rosenfield AT, Zeman RK, Cicchetti DV, Siegel NJ (1985) Experimental acute tubular necrosis: US appearance. Radiology 157(3):771-774 
33. Bittard H, Benoit G, Moukarzel M, Charpentier B, Ecoffey C, Fries $D$ et al (1991) Decrease in renal vascular resistance in University of Wisconsin solution preserved kidney transplants. J Urol 146(1):1-4

34. Chan TY, Epstein JI (2004) Radiation or chemotherapy cystitis with "pseudocarcinomatous" features. Am J Surg Pathol 28(7):909-913

35. Thrasher JB, Crawford ED (1992) Complications of intravesical chemotherapy. Urol Clin North Am 19(3):529-539

36. Capps GW, Fulcher AS, Szucs RA, Turner MA (1997) Imaging features of radiation-induced changes in the abdomen. Radiographics: Rev Publ Radiol Soc North Am, Inc 17(6):14551473

37. Wong-You-Cheong JJ, Woodward PJ, Manning MA, Davis CJ (2006) From the archives of the AFIP: inflammatory and nonneoplastic bladder masses: radiologic-pathologic correlation. Radiographics: Rev Publ Radiol Soc North Am, Inc 26(6):18471868

38. Stillwell TJ, Benson RC Jr (1988) Cyclophosphamide-induced hemorrhagic cystitis. A review of 100 patients. Cancer 61(3):451457

39. Lawson M, Vasilaras A, De Vries A, Mactaggart P, Nicol D (2008) Urological implications of cyclophosphamide and ifosfamide. Scand J Urol Nephrol 42(4):309-317

40. Ansari M, Theoret Y, Rezgui MA, Peters C, Mezziani S, Desjean C et al (2014) Association between busulfan exposure and outcome in children receiving intravenous busulfan before hematopoietic stem cell transplantation. Ther Drug Monit 36(1):93-99

41. Grellety T, Houede N, Hoepffner JL, Riviere J, Merino C, Lieutenant V et al (2014) Hemorrhagic cystitis in patients treated with cabazitaxel: a radiation recall syndrome? Ann Oncol: Off $\mathrm{J}$ Eur Soc Med Oncol / ESMO 25(6):1248-1249

42. Vose JM, Reed EC, Pippert GC, Anderson JR, Bierman PJ, Kessinger A et al (1993) Mesna compared with continuous bladder irrigation as uroprotection during high-dose chemotherapy and transplantation: a randomized trial. J Clin Oncol: Off J Am Soc Clin Oncol 11(7):1306-1310

43. Shepherd JD, Pringle LE, Barnett MJ, Klingemann HG, Reece DE, Phillips GL (1991) Mesna versus hyperhydration for the prevention of cyclophosphamide-induced hemorrhagic cystitis in bone marrow transplantation. J Clin Oncol: Off J Am Soc Clin Oncol 9(11): 2016-2020

44. McCarville MB, Hoffer FA, Gingrich JR, Jenkins JJ 3rd (2000) Imaging findings of hemorrhagic cystitis in pediatric oncology patients. Pediatr Radiol 30(3):131-138

45. Marks LB, Carroll PR, Dugan TC, Anscher MS (1995) The response of the urinary bladder, urethra, and ureter to radiation and chemotherapy. Int J Radiat Oncol Biol Phys 31(5):1257-1280

46. Kelly RJ, Billemont B, Rixe O (2009) Renal toxicity of targeted therapies. Target Oncol 4(2):121-133 